\title{
ATUALIZAÇÃO DA AÇÃO SINDICAL PARA OS DESAFIOS DA CONTEMPORANEIDADE
}

\section{UNION ACTION UPDATE FOR THE CHALLENGES OF CONTEMPORANEITY}

\author{
Marcia Regina Lobato ${ }^{1}$ \\ Vitor Salino de Moura Eça ${ }^{2}$
}

\section{RESUMO}

O presente artigo tem como propósito analisar o modelo sindical brasileiro na contemporaneidade, iniciando-se pela definição doutrinária de sindicato, seguindo-se pela abordagem de sua evolução histórica e da regulamentação do sindicalismo no ordenamento jurídico pátrio. Tratar-se-á do modelo vigente, assim como de suas funções e prerrogativas dominantes, em consonância com a sua finalidade precípua, mormente a de representar e defender os direitos e interesses dos trabalhadores, em todos os segmentos de ocupação. Será demonstrada a importância do papel dos sindicatos no procedimento das negociações coletivas laborais para a promoção de ajustes entre o capital e o trabalho visto que, sem a sua presença os pactos não se realizariam. A atual conjuntura socioeconômica por que passa o Brasil afeta sobremaneira todos os assalariados que muito comumente têm surpreendido com a ameaça de desemprego. Tal situação conduz à necessidade de um debate com o fito de invocar a força sindical para negociar, mesmo que em uma situação de desequilíbrio. Isso propicia o diálogo entre as categorias profissional e econômica, a fim de sugerir soluções para os desafios característicos de tempos de crise, de modo a assegurar o maior número de postos de trabalho e, assim, evitar o retrocesso na busca de uma sociedade mais justa, equânime, solidária e condescendente.

Palavras-chave: Sindicalismo, Contemporaneidade, Manutenção dos postos de trabalho

\begin{abstract}
This article has the purpose of analyzing the Brazilian union model in contemporary times, starting with the doctrinal definition of union followed by the approach of its historical evolution and regulation of unionism in the Brazilian legal system. The current model will be described, as well as its main functions and prerogatives, in line with its primary purpose, especially regarding the representation and defense of rights and interests of workers, in every occupation segment. The work will also contemplate the important role of unions in the procedure of labor collective negotiations to promote adjustments between capital and labor, since the deals would not take place without its presence. The current socioeconomic situation experienced by Brazil greatly affects all employees who very often have been surprised with the fear of unemployment. This situation leads to the need for a debate with a purpose of invoking union power to negotiate, even in an unbalanced situation. This favors the dialogue between professional and economic categories, in order to suggest solutions to the challenges

\footnotetext{
${ }^{1}$ Doutoranda em Direito pela Pontifícia Universidade Católica de Minas Gerais - PUC/MG, Minas Gerais, (Brasil) Professora pela Pontifícia Universidade Católica de Minas Gerais - PUC/MG, Minas Gerais, (Brasil). E-mail: marciafr@trt3.jus.br

${ }^{2}$ Pós Doutorado em Direito Processual Comparado pela Universidad Castilla - La Mancha - UCLM, Castilla - La Mancha, (Espanha). Juiz do Trabalho Titular - Tribunal Regional do Trabalho - 3a. Região - MG, Minas Gerais, (Brasil), professor pela Pontifícia Universidade Católica de Minas Gerais - PUC/MG, Minas Gerais, (Brasil). Email: profvitorsalino@gmail.com
} 
that commonly arises with times of crisis, to ensure the greatest number of jobs and, thus, to avoid the recess in the search for a more just, equitable, compassionate and condescending society.

Keywords: Unionism, Contemporaneity, Maintenance of employment 


\section{CONSIDERAÇÕES INICIAIS}

Sabe-se que, da mesma forma em que os homens passam a ter atividades profissionais diferenciadas, com ambições e projeções matizadas, igualmente os vínculos que os unem vão se alterando, evidenciando as desigualdades latentes.

Nesse contexto, pode-se afirmar que, tanto os trabalhadores quanto os empregadores, isoladamente, pouco podem fazer na luta por seus interesses profissionais ou econômicos, tornando-se vantajosa, portanto, a associação como um meio hábil para fortalecer as suas reivindicações.

Inescusável a essa aproximação, tomando como ponto de partida os interesses profissionais ou econômicos afins, são os sindicatos definidos pela norma celetista como

a associação para fins de estudo, defesa e coordenação dos seus interesses econômicos ou profissionais de todos os que, como empregadores ou empregados, agentes ou trabalhadores autônomos, ou profissionais liberais, exerçam, respectivamente, a mesma atividade ou profissão ou atividades ou profissões similares ou conexas (caput do art. 511 da Consolidação das Leis do Trabalho - CLT).

Evidencia, ainda, o $\S 2^{\circ}$ do citado artigo, como característica agregativa da categoria profissional, a semelhança de condições de vida decorrentes da profissão ou do labor em comum, em situação de trabalho na mesma atividade econômica ou, ainda, atividades equivalentes ou conexas. A organização baseada na solidariedade de "interesses econômicos dos que empreendem atividades idênticas, similares ou conexas", constitui assim a denominada categoria econômica, com supedâneo no $\S 1^{\circ}$ do mesmo dispositivo.

Assim, tais entidades representam os trabalhadores que se unem por interesses profissionais comuns, vislumbrando solucionar os impasses coletivos laborais com o objetivo de alcançar melhores condições de trabalho e, por conseguinte, de vida.

Noutra perspectiva, é inegável que o amparo legal às relações de emprego e de trabalho no País tem como base normas imperativas, como se infere do comando constitucional estabelecido no rol do seu artigo $7^{\circ}$, bem como na Consolidação das Leis do Trabalho. É 
também a própria legislação celetista que faculta aos sindicatos, na qualidade de representantes da categoria profissional, a celebração de Convenção Coletiva de Trabalho em face do sindicato econômico correlato, ou de uma ou mais empresas correspondentes à categoria patronal, disciplinando as condições de trabalho aplicáveis na esfera das respectivas representações ou no âmbito da(s) empresa(s) acordante(s).

Destarte, cabe assinalar que os direitos fundamentais e sociais dos trabalhadores assegurados em lei têm por escopo estatuir garantias mínimas. Ressalte-se que alguns desses direitos são inderrogáveis e, portanto, não são objeto da liberdade convencional entre as partes. Exemplificam-se os direitos ao descanso e à proteção à integridade física, ambos garantidos pela legislação. Mas é possível estabelecer por meio das negociações coletivas entre entidades sindicais equivalentes normas e condições de trabalho não previstas em lei, respeitando-se o mínimo legal exigido.

O sindicalismo brasileiro contemporâneo passa, todavia, por um momento de letargia diverso daquele de outrora, quando demonstrava enorme capacidade de articulação nos mais variados setores da sociedade, inflando os movimentos sócio-laborais em busca de ganhos para a classe trabalhadora.

Assim, a atuação sindical como representante da categoria profissional deverá ser analisada considerando-se, especialmente, a atual conjuntura socioeconômica, as diversidades das demandas emergentes da globalização, e à luz dos princípios constitucionais que possibilitem a construção de uma militância capaz de garantir melhores condições laborais, em prol do fortalecimento da dignidade dos trabalhadores em todas as esferas de ocupação.

Para tanto, serão abordados, os conceitos, a legislação e a evolução histórica, o modelo sindical vigente no País, as prerrogativas e funções precípuas dos entes sindicais, para, após, adentrar o papel dos sindicatos frente às negociações coletivas. E, a partir daí, expostas as considerações pertinentes, vislumbra-se a importância de se questionar e debater o desempenho da representatividade sindical em face do momento da crise pela qual passa o Brasil e os reflexos daí decorrentes, que afetam sobremaneira o mundo do trabalho. 


\section{SINDICATO}

\subsection{CONCEITUAÇÃO}

A definição de sindicato construída pela doutrina considera a presença das entidades profissionais e empresariais, ampliando o conceito de modo a alcançar ambos os polos trabalhistas. De um lado os trabalhadores, cujo objetivo é salvaguardar os seus interesses individuais e coletivos bem como a promoção social e, de outro, os empregadores, estes com intuito de defender os interesses econômicos e o desenvolvimento organizacional.

Nestor de Buen Losano (1977, p. 599) sustenta que "sindicato é a pessoa social, livremente constituída por trabalhadores ou por patrões, para a defesa de seus interesses de classe".

Nessa perspectiva, os sindicatos representam os interesses gerais da categoria econômica ou profissional, bem como os interesses particulares de seus afiliados, com o escopo de tutelar os benefícios daqueles que os integram.

Alfredo Ruprecht (1995, p. 135) aduz que "o sindicato operário é a reunião permanente de pessoas físicas de uma mesma profissão, ofício ou atividade, para a defesa e melhoria dos interesses profissionais".

Assim, é possível extrair das citações doutrinárias apontadas o conceito de sindicato com as seguintes concepções: associação, representação e tutela de interesses coletivos de trabalhadores e de empregadores.

Vale salientar que, para definir os institutos regulados pelo Direito, faz-se necessário considerar as particularidades normativas vivenciadas no decorrer da evolução histórica de cada sociedade. Infere-se daí que, na conceitualização de sindicato, no caso brasileiro, está também implícita a ideia de categoria, relativamente ao sistema jurídico vigente no País.

Nesse cenário, a Consolidação das Leis do Trabalho (CLT) traçou características inerentes ao sindicato estabelecendo, no caput de seu artigo 511, a licitude da associação e suas finalidades, elucidando tal associação, conforme os termos registrados no tópico antecedente. 
Destarte, o sindicato profissional pode ser compreendido como uma associação permanente de diversos indivíduos, os quais desempenham atividades profissionais no mesmo segmento e que pactuam no sentido de se organizarem com objetivo de defender os interesses sociais, econômicos e profissionais pertinentes às atividades laborais por eles exercidas.

\subsection{SINDICALISMO NO BRASIL: EVOLUÇÃO HISTÓRICA E LEGISLATIVA}

O modelo sindical de um país, em seus diversos ângulos, retrata a realidade dentro da qual ele surge e se desenvolve. Com efeito, são vários os elementos que contribuem para a cultura sindical de cada época. Além dos fatores sociais, econômicos e políticos, consideramse também as tradições histórico-trabalhistas como elementos determinantes de tal cultura.

No caso brasileiro, a origem do sindicato tem raízes no meio rural que, posteriormente, alavancou-se para os centros urbanos. A economia, baseada nas atividades agrícolas, contava com uma industrialização incipiente e as relações de trabalho havidas eram similares às dos senhores de terras e seus escravos. Não havia espaço para qualquer agrupamento de operários, tampouco para a formação de sindicatos, pois as raras atividades existentes à época se desenvolviam lentamente e a densidade demográfica era desigual. Ademais, os meios de comunicação, assim como os de transporte, eram deficitários e incapazes de propiciar contatos entre os operários, bem como a consolidação de movimentos consistentes.

Findo o período escravocrata, desponta uma classe trabalhadora juridicamente livre e, nesse cenário, a primeira Constituição Brasileira, depois da proclamação da República, promulgada em 24 de fevereiro de 1891, indicava a liberdade de associação, como se infere do $\S 8^{\circ}$ do seu artigo 72: “A todos é licito associarem-se e reunirem-se livremente e sem armas, não podendo intervir a polícia senão para manter a ordem pública”.

Ocorre que não há registro histórico acerca de formação consistente e destacada de desempenho de práticas coletivas nesse tempo, muito embora se saiba que o processo de construção de identidade coletiva se dava por meio de pequenas lutas que se forjam nos locais 
de trabalho e de moradia, e se convertem em movimentos mais amplos e abrangentes, segundo ensinamentos de Maria Manfredi (1996, p. 23).

O setor agrário, abalado com o fim do período escravocrata, necessitava de incentivos para se reorganizar. Por essa razão, o Estado, com objetivo de promover o associativismo, em meados de 1903, sancionou o Decreto n. 979, contemplando em seu artigo $1^{\text {o }}$, in verbis: “É facultado aos profissionais da agricultura e indústrias rurais de qualquer gênero organizarem entre si sindicatos para estudo, custeio da defesa de seus interesses". Em seguida, o Decreto n. 1.637, de 5 de janeiro de 1907, criou sindicatos profissionais e sociedades cooperativas e em seu artigo $1^{\circ}$ facultava aos profissionais exercentes de profissões equivalentes a se organizarem, com a finalidade de defender os interesses profissionais de seus associados.

Muito embora tais Decretos tenham consentido as reuniões entre os trabalhadores com objetivo de promover a luta por seus direitos laborais, poucos foram os benefícios alcançados naquele período, em decorrência da ausência de uma cultura sindical, o que os levava a não reivindicarem melhorias nas condições nas condições de trabalho.

Segadas Viana (1991, p. 967) sustenta que, nessa fase embrionária, o sindicalismo brasileiro "nunca chegou a ter uma real expressão", tendo em vista que as indústrias rurais eram escassas e, como resultado, a massa operária era inexpressiva acarretando ausência de luta de classes.

No mesmo compasso, Alice Monteiro de Barros (2008, p. 1210) afirma que havia um predomínio do trabalho rural, e que a indústria era incipiente no Brasil e, assim, as primeiras legislações foram destinadas ao setor agrícola.

Com o fim da escravidão, tornou-se necessário trazer estrangeiros para substituir a mão de obra anteriormente utilizada. Com isso, a influência da imigração, especialmente dos italianos, contribuiu para a disseminação da doutrina anarcossindicalista ${ }^{3}$, inspirando no movimento sindical brasileiro ideias revolucionárias, $\mathrm{o}$ fomento de movimentos paredistas e de reivindicações por melhores condições de vida. Houve influência direta de 
tais imigrantes, considerando-se que, até então, a atuação sindical no País era irregular e desordenada, carecendo, pois, de delimitações e especificações de seus objetivos.

Com efeito, a evolução das relações de trabalho e sindicais se evidenciaram nos fins da década de 1920 e início da de 1930, em razão da crise decorrente do setor cafeeiro em 1929, período em que o centro econômico do País concentra-se na região Sudeste, especialmente em Minas Gerais e São Paulo, que passa a auferir o maior número de investimentos no setor industrial.

Nessa fase, o País diminuiu a sua capacidade de importar bens de consumo, impondose uma necessária industrialização, surgindo a classe empresarial. De igual maneira, inicia-se um processo de urbanização e, gradualmente, há um incremento dos meios de transporte, a acumulação de capitais e uma migração acentuada de pessoas da área rural para as cidades.

Diante do aumento populacional nos centros urbanos, as concentrações operárias naturalmente passaram a ocupar lugar relevante, questão social que preocupou o governo. As atividades sindicais cresciam concomitantemente ao desenvolvimento industrial, apesar de irregulares e sujeitas a intermitentes repressões policiais.

Com o intuito de controlar a classe operária, o Estado passou a regulá-la minuciosamente a partir de 1930. Deliberou então por organizar e monitorar as relações de trabalho e sindicais com uma severa intervenção estatal, obstando os movimentos da classe obreira na luta por melhores condições laborais. Assim, o Estado cria e estabelece diretrizes destinadas aos sindicatos com objetivo de conter as possíveis paralisações dos operários, adota medidas de cunho social para suavizar a interação entre os trabalhadores e empregadores, conferindo aos sindicatos o papel de colaborar com o poder público, e, ao mesmo tempo sujeitando-os ao seu controle, como pontua Amauri Mascaro Nascimento (2000, p. 77).

\footnotetext{
3 Anarcossindicalismo: "Doutrina sindical e política que influenciou, poderosamente, o sindicalismo revolucionário [...] Sua mensagem centralizava-se em alguns pontos conhecidos: a ideia do combate ao capitalismo, a evanescência do Estado, a desnecessidade da existência de leis jurídicas para governar a sociedade, o combate ao governo e à autoridade, a ação direta como meio de luta, enfim, uma radical crítica a tudo quanto existia na ordem jurídica, política e social”. (NASCIMENTO, 2000, p.77-78).
} 
A partir de 1931, a sindicalização passa a ser regulada pelo Decreto n. 19.770, dandolhe contornos mais precisos e distinguindo com mais clareza as atribuições dos sindicatos profissionais e econômicos, impondo-lhes o necessário reconhecimento pelo Ministério do Trabalho, Indústria e Comércio. A partir dessa legislação, as convenções coletivas de trabalho passam a ser prerrogativas atribuídas aos sindicatos.

A Constituição de 1937 incorporou ao sistema brasileiro o modelo de organização sindical italiano, proveniente da Carta Del Lavoro. Segundo Joselita Nepomuceno Borba (2013, p. 156),

a regulamentação do sindicalismo, doravante, deu-se de acordo com os princípios corporativistas: sindicato como pessoa jurídica de direito público submetido ao controle do poder público, unicidade sindical, eficácia erga omnes dos contratos coletivos, poder normativo da Justiça do Trabalho, proibição da greve e do lockout e, desta forma, o modelo foi transferido para a CLT.

Assim, o desempenho dos sindicatos permanecia submetido ao Estado e subordinavase literalmente ao Ministério do Trabalho, Indústria e Comércio, o qual tinha o controle absoluto do funcionamento da entidade sindical.

Em 1946 o Brasil promulga uma nova Constituição, a qual reconhece o direito de greve e estatui a liberdade de associação sindical, silenciando-se, todavia, sobre a unicidade e pluralidade sindical.

Durante o período entre os anos de 1946 e 1964, os trabalhadores manifestavam-se por meio de seus sindicatos de várias formas, culminando em movimentos grevistas.

A fase que se seguiu a 1964 representou acentuada repressão à classe trabalhadora. As intervenções alcançaram um contingente expressivo de entidades sindicais. Tal interferência foi acompanhada de uma política cujos reajustes não equiparavam aos índices inflacionários.

Nesse período histórico, sustenta Ronaldo Lima Santos (2012, p. 51) que o Estado buscou impor aos sindicatos uma postura assistencialista ao invés de reivindicatória, em que se buscava a promoção social dos trabalhadores, concedendo-lhes entre outros benefícios assistência médico-hospitar, cooperativas e creches. 
Alice Monteiro de Barros (2008, p. 1212) afirma que, após a implementação do regime militar em 1964, com nova Constituição promulgada em 1967, permanece assegurada a liberdade de associação profissional, similar aos moldes traçados pela Carta de 1946. O direito de greve é assegurado no art. 158, XXI, salvo nos casos serviços públicos e nas atividades consideradas legalmente essenciais.

Nas décadas de 1970 e 1980, surge um novo sindicalismo que resgata as comissões de fábricas e propõe um novo modelo sindical, mais ativo, o qual deu início aos movimentos sociais em todo o território nacional.

Após o advento da Constituição Federal de 1988, o sindicalismo ganhou novo status, no entanto a organização sindical conservou traços da estrutura inspirada no modelo ancião e sedimentada na Consolidação da Legislação do Trabalho.

Muito embora a organização sindical tenha passado por interferências do Estado até alcançar um sistema que, a priori, pode ser considerado como um modelo sindical parcialmente livre, na medida em que o ente sindical ganhou autonomia negocial e organizacional, ainda restam vestígios do modelo corporativista a exemplo da unicidade sindical, o que obsta um sindicalismo efetivamente livre e pluralista, necessário ao desenvolvimento do setor trabalhista.

\section{ORGANIZAÇÃO SINDICAL BRASILEIRA ATUAL}

\subsection{ESTRUTURA SINDICAL VIGENTE}

A Constituição Federal de 1988 veda a interferência e a intervenção na organização sindical, afirmando a autonomia dos sindicatos.

A organização sindical é piramidal; em sua base estão sindicatos; em seu meio estão as federações e, em sua cúpula encontram-se as confederações.

$\mathrm{Na}$ base do sistema sindical encontram-se os sindicatos, cuja organização se dá por categoria profissional ou diferenciada no que se refere aos trabalhadores, e por categoria 
patronal, o qual se organizam os empregadores. Tais sindicatos têm como espaço territorial mínimo o município. Ressalte-se que, na hipótese de base territorial mais ampla, formam-se os sindicatos nacionais, conforme se extrai do inciso II, art. $8^{\circ}$ da Constituição Federal.

As federações derivam da união de, no mínimo, cinco sindicatos da mesma categoria profissional, econômica ou diferenciada (artigo 534 da CLT). Localizam-se nas capitais de cada Estado, cujo objetivo é propor critérios para a defesa dos interesses do sindicatos patronais e profissionais.

Já no caso das confederações, fazem-se necessárias pelo menos três federações para a sua formação, respeitadas as respectivas categorias. A sede das confederações se encontra em Brasília - DF, e elas têm como propósito apresentar as diretrizes para defesa dos interesses da categoria, em todo o território nacional.

No que tange à estrutura interna, a Consolidação das Leis do Trabalho estabelece que a administração dos sindicatos será desempenhada por uma diretoria e que terá em sua composição, no mínimo, três membros e, no máximo, sete, além de um conselho fiscal composto por três membros (artigo 522 da CLT).

Os dispositivos celetistas que estabelecem o número de dirigentes sindicais, no entanto, não foram revogados e, por essa razão, a quantificação preconizada pela legislação infraconstitucional prevalece enquanto não advier retificação, se for o caso, por meio de um novo texto legal.

\subsection{DO REGISTRO SINDICAL}

Após a Constituição da República de 1988, a criação, o registro e o funcionamento dos entes sindicais passaram por significativas alterações.

A liberdade conferida aos sindicatos deve ser entendida como o direito que tais organizações têm de governar-se. Até a presente data, contudo, o Brasil não ratificou a Convenção n. 87 da Organização Internacional do Trabalho (OIT), que define a liberdade 
sindical como o direito de os próprios sindicatos elaborarem seus estatutos, seus regulamentos administrativos, de escolher livremente os seus representantes, de dispor sobre sua gestão e sua atividade, bem como de formular o seu programa de ação - artigo $3^{\circ}$.

A Lei Maior dispõe no inciso I, artigo $8^{\circ}$, a expressa vedação ao Estado de interferência e de intervenção na organização sindical, exceto pela determinação do seu "registro no órgão competente." (grifo nosso).

Houve, todavia, controvérsias doutrinárias no que tange à interpretação de qual seria o "órgão competente" apontado pelo mencionado dispositivo para que se promova o registro sindical. Essa divergência emergiu da própria norma constitucional, uma vez que, ao mesmo tempo em que expressamente coíbe a intervenção estatal, ressalva o seu registro em órgão competente, conquanto não tenha editado lei para regulamentar a matéria.

Ronaldo Lima dos Santos (2012, p. 54) afirma que se extinguiu a competência do Ministério do Trabalho, de maneira que os sindicatos passam a adquirir personalidade jurídica com o simples registro de seus atos constitutivos no Registro Civil de Pessoas Jurídicas, sem embargo da necessidade de registro da entidade sindical dever ser feito perante o Ministério do Trabalho, no qual deve ser feito o depósito do estatuto sindical, já que o registro civil confere apenas personalidade jurídica.

O Supremo Tribunal Federal (STF), com o fito de salvaguardar o regime de unicidade sindical, pacificou a questão por meio da Súmula n. 677, nos seguintes termos: "Até que a lei venha a dispor a respeito, incumbe ao Ministério do Trabalho proceder o registro das entidades sindicais e zelar pela observância do princípio da unicidade sindical". (Sessão Plenária de 24/09/2003 - publicado nos dias 9, 10 e 13 de outubro de 2003).

Destarte, o Ministério do Trabalho passou a ser o órgão competente para a concessão do Registro Sindical às categorias representativas (econômica ou profissional) zelando, pois, pela unicidade sindical.

Tal atribuição não implicaria ingerência do Poder Público na organização sindical, mas sim de um meio de impedir que em única base territorial ocorra a criação de mais de um 
sindicato representante da mesma categoria profissional, patronal ou específica. Coadunando com essa afirmação, Ronaldo Lima dos Santos (2012, p. 54) afirma que a exigência do depósito do estatuto do sindicato no Ministério do Trabalho não viola o princípio da liberdade sindical, considerando- se que existe previsão legislativa de registros específicos e especiais a determinadas pessoas jurídicas ou naturais que desempenham determinadas atividades profissionais ou atividades específicas, a exemplo do registro dos partidos políticos na Justiça Eleitoral - o que agrega à pessoa jurídica do partido político a capacidade de representação política, em conformidade com o $\S 2^{\circ}$ do art. 17 da Constituição Federal $^{4}$ de 1988.

Insta salientar que a autonomia conferida constitucionalmente aos sindicatos lhes permitiu, dentre outras atribuições, a da organização de seus próprios estatutos, bem como a de sua aprovação. Essa liberdade implica, ainda, a circunstância de os entes sindicais terem o direito de escolherem livremente os seus dirigentes, sem sujeição a quaisquer exigências para o exercício do direito de voto, elegibilidade e procedimentos estabelecidos nos artigos 529, 530, 531 e 532 da Consolidação das Leis do Trabalho, revogados em razão do que dispõe o inciso I do art. $8^{\circ}$ da Constituição Federal de 1988, conforme Alice Monteiro de Barros (2008, p. 1228).

É incontestável que, após a Constituição de 1988, ocorreram mudanças significativas no modelo sindical adotado no País. Os entes sindicais passaram a participar de modo mais atuante, apesar de a autonomia continuar a sofrer restrições em decorrência das características corporativistas preservadas no ordenamento jurídico, a exemplo da contribuição sindical compulsória.

Frise-se que tais limitações à autonomia dos sindicatos, não os impede de cumprir os seus papéis. De qualquer modo, é imprescindível que o Brasil ratifique a Convenção 87 da OIT e, por conseguinte, adote in totum o princípio da liberdade sindical.

\footnotetext{
${ }^{4} \mathrm{CF} / 88-\S 2^{\circ}$ do art. 17: "Os partidos políticos, após adquirem personalidade jurídica, na forma da lei civil, registrarão seus estatutos no Tribunal Superior Eleitoral".
} 


\subsection{DAS FUNÇÕES DOMINANTES E PRERROGATIVAS}

Com a edição da Consolidação das Leis do Trabalho em 1943, algumas leis preexistentes nela foram incorporadas, a exemplo das legislações pertinentes à organização e ao enquadramento sindical - Decretos-lei 1.402, de 1939 e 2.381, de 1940, respectivamente. Naquela época, as funções e prerrogativas dos sindicatos retratavam o regime político vigente, cujo traço marcante era o controle absoluto e a negativa da livre criação de sindicatos e da plenitude de sua autonomia, impondo aos entes sindicais, no ato do exercício de suas funções, o endosso estatal.

Assim, a CLT regulamentou as prerrogativas dos sindicatos, intervindo em sua dinâmica funcional, perdurando tal situação até meados da década de 1980, ocasião em que movimentos sociais se insurgiram contra as sucessivas restrições à liberdade sindical.

Desse modo, a Constituição Federal de 1988 surgiu como instrumento libertador do modelo instituído por Getúlio Vargas, modernizando, ainda que em parte, o sistema sindical, ao revogar alguns dos dispositivos da norma celetista, particularmente os de natureza restritiva, concedendo mais autonomia aos sindicatos e vedando a interferência do Estado na sua organização e na sua administração.

Para o desenvolvimento das funções e prerrogativas conferidas aos entes sindicais é imperiosa a delimitação criteriosa de suas possibilidades. Para tanto, é necessário estabelecer normas que, efetivamente, possam garantir o cumprimento e a realização de seus objetivos.

Com base nessa premissa, vale assinalar a disposição constitucional insculpida no inciso III do artigo $8^{\circ}$, segundo a qual "ao sindicato cabe a defesa dos direitos e interesses coletivos ou individuais da categoria, inclusive em questões judiciais ou administrativas". Podese afirmar que essa é a mais importante função (prerrogativa) dos sindicatos, isto é, a de representação da categoria, considerando-se que a organização do sindicato tem como pressuposto agir e responder em nome da categoria, velando especialmente pelos interesses envolvidos nas relações de trabalho. 
Nesse sentido, a alínea "a" do artigo 513 da CLT dispõe que os sindicatos devem representar os interesses gerais da categoria ou profissão liberal, ou os interesses individuais de seus associados junto às autoridades judiciárias e às administrativas, mormente no que se refere ao exercício das atividades profissionais. Essa é uma representação legal e não espontânea, na qual a outorga de tais poderes é conferida diretamente pelo Estado.

Cumpre sublinhar que o ordenamento jurídico brasileiro concede aos entes sindicais quer a condição de representante, quer a condição de substituto processual. $\mathrm{Na}$ primeira possibilidade, o ente sindical necessita de autorização de seus associados e, na segunda, o sindicato age em nome próprio, mas em prol de terceiro, independentemente de concessão de poderes dos representados. Dessa forma, Vitor Salino de Moura Eça (2007, p. 219-234), ao tratar da substituição processual, destaca que se trata de "legitimação extraordinária, caracterizada pela imprescindibilidade de autorização legislativa".

Outra importante prerrogativa dos sindicatos é a possibilidade de celebrar acordos e convenções coletivas $-\S 2^{\circ}$ do artigo 611 da CLT. Por meio das negociações coletivas os entes sindicais profissionais buscam entendimento com os empregadores, vislumbrando a celebração de ajustes contendo normas jurídicas aplicáveis às relações de trabalho firmadas entre os membros das categorias convenentes.

Faz, ainda, parte do rol de funções relevantes atribuídas aos sindicatos, a assistencial, consistindo esta na prestação de serviços diversos aos seus associados, colaborando para o crescimento do ser humano, a exemplo de educação, lazer, serviços jurídicos dentre outros.

Ao exercer a sua prerrogativa parafiscal, arrecadadora, o sindicato impõe aos que participam das categorias profissionais e econômicas contribuições financeiras, com objetivo de arrecadar recursos para custear as suas atividades; seja para financiar os serviços assistenciais ofertados, seja para angariar fundos para promoção de greves. As fontes de receita para tal finalidade decorrem da contribuição sindical - inciso IV do artigo $8^{\circ}$ da CF/88 e regulamentada pelo artigo 513 da CLT - além da contribuição confederativa autorizada pelo texto constitucional em seu inciso IV do artigo $8^{\circ}$ da contribuição assistencial e da mensalidade sindical. 
Verifica-se que a contribuição sindical decorre de imposição legal e alcança todos os trabalhadores. Equivale a um dia de remuneração do trabalhador, descontada anualmente e depositada em estabelecimento bancário para integrar recursos do Fundo de Amparo ao Trabalhador (FAT). Tem por finalidade, ainda, o custeio das atividades desenvolvidas pelos sindicatos.

A contribuição assistencial ou taxa assistencial advém da vontade das partes, visto que é autorizada em assembleia geral do sindicato realizada para esta finalidade. Origina-se das contribuições pagas tanto pelos membros da categoria profissional quanto da econômica, associados ou não a entidade sindical.

Já as mensalidades sindicais são contribuições voluntárias e abrangem apenas os membros associados e se traduzem em liberalidade dos trabalhadores filiados.

As funções e prerrogativas assinaladas não exaurem a diversidade da ação sindical, tendo em vista que os seus objetivos e modos de atuação dependem das particularidades de cada tempo e de cada local.

\section{MODELO SINDICAL BRASILEIRO: FORTALECIDO OU DEPAUPERADO?}

\subsection{O SINDICATO E O DIREITO DO TRABALHO}

A análise do modelo sindical brasileiro pressupõe o exame concomitante do Direito do Trabalho no ordenamento jurídico pátrio no que tange às distinções e aplicabilidades, englobando as suas ramificações, isto é, o Direito Coletivo e o Individual.

Define-se como Direito do Trabalho como o conjunto de normas, de regras e de princípios jurídicos que conduzem as relações havidas entre trabalhador e empregador, bem como de ambos perante o Estado, para fins de tutela e proteção do labor.

Trata-se de um dos ramos do Direito, cujo objetivo é direcionado para aprimorar as exigências de ajustes nas relações da força laboral no sistema socioeconômico. 
Parte da doutrina sustenta ser o Direito Coletivo do Trabalho, igualmente denominado Direito Sindical, ramo do Direito do Trabalho, que por sua vez comporta também o Direito Individual do Trabalho.

Perfilha esse entendimento Antônio Ferreira Cesarino Júnior (1980, p. 52) para quem o Direito Individual "é o conjunto de leis que consideram individualmente o empregado e o empregador, unidos numa relação contratual", ao passo que o Direito Coletivo, segundo o citado autor, é definido como o "conjunto de normas que consideram os empregados e os empregadores coletivamente reunidos, principalmente na forma de entidades sindicais".

Sendo assim, verifica-se que como ramo do Direito do Trabalho, o Direito Individual implica uma relação entre o trabalhador e seu empregador, como sujeitos de direitos e obrigações, levando em conta os interesses de indivíduos determinados. Ao contrário, no Direito Coletivo, a relação entre os sujeitos de direito leva em conta a participação do indivíduo como membro de dada coletividade, cujos interesses grupais são abstratos.

Já Amauri Mascaro do Nascimento (1989, p. 323) alega que o Direito Coletivo do Trabalho é desprovido de autonomia legislativa, jurisdicional, didática e doutrinária. Além do mais, suas normas encontram-se agrupadas na Consolidação das Leis do Trabalho, o mesmo diploma do Direito Individual do Trabalho e, de igual maneira, situa-se no mesmo capítulo da Constituição Federal de 1988, destinado a este último.

Insta salientar que o Direito Coletivo do Trabalho possui institutos a ele inerentes e aplicáveis exclusivamente a esse ramo do Direito, a exemplo das negociações coletivas do trabalho e das diversas modalidades de dissídios coletivos, a exemplo dos dissídios coletivos de natureza econômica, de greve, jurídico, entre outros.

Os sindicatos, por seu turno, como instituições do Direito Coletivo do Trabalho, têm objetivos distintos, destacando-se como uma de suas finalidades essenciais o estabelecimento das condições de trabalho por meio dos acordos e convenções coletivas de trabalho, vislumbrando a melhoria das condições laborais e de vida de todos os trabalhadores. Além disso, deve-se registrar a assistência aos membros da categoria e a defesa de seus interesses. Ao 
lado de tais fins, considerados basilares, podem ser enumerados outros secundários, como a participação dos trabalhadores na gestão das empresas.

Para Márcio Túlio Viana (2003, p. 354) “seja como for, o sindicato se revelou, desde cedo, a principal fonte do Direito do Trabalho - seja no aspecto material, forçando a criação de novas normas, seja também, de certo modo, sob o aspecto formal, criando ele próprio essas normas, pela convenção coletiva". Prossegue ele assegurando que, mesmo em períodos ou locais em que o direito surgiu de modo autoritário, o sindicato, de alguma maneira, esteve presente.

Pode-se afirmar que a participação do sindicato não se circunscreve apenas como fonte do direito, quer sob o prisma material, quer do ponto de vista formal, mas também como meio de tornar efetiva a aplicação das normas e, para tal, imprescindível estar ao lado dos trabalhadores, auxiliando-os e defendendo-os.

\subsection{AS NEgOCiaÇÕES COLETIVAS TRABALHistas E $\mathrm{O}$ PAPEL DOS SINDICATOS}

Um dos mais importantes instrumentos de solução de conflitos trabalhistas na atual sociedade são as negociações, que são consideradas das mais relevantes modalidades de autocomposição de lides trabalhistas de natureza coletiva. Em tais casos, os representantes do trabalho e os do capital buscam solucionar o desentendimento para que se realizem contratos coletivos, acordos ou convenções coletivas de trabalho, que estabelecem condições de trabalho de aplicação cogente nos contratos individuais entre os integrantes dos grupos convenentes, observando-se, entretanto, as condições mínimas legais.

Os procedimentos das negociações coletivas são norteados à luz de princípios inerentes ao direito e que têm por escopo servir de esteio na construção de normas direcionadas à edificação dos ajustes entabulados entre as partes envolvidas no conflito laboral.

Nesse sentido, vale destacar a importância do princípio da boa-fé ou da lealdade, cujo corolário é o dever formal de negociar, consolidado na obrigação da análise das propostas 
recíprocas, bem como na elaboração de contraproposta compatível, devendo as partes apresentar argumentos que justifiquem os motivos de eventual rejeição, fundamentar os pleitos e as razões de suas propostas.

Assim sendo, as negociações coletivas instigam as partes a cederem e também a perceberem o lado adverso e, ao mesmo tempo, a se conduzirem pela via do colóquio e do entendimento, ao invés dos caminhos da discórdia e do conflito.

Importante sublinhar, ainda, que as negociações devem-se realizar em ambiente de paz e de harmonia, que a greve deverá ser deflagrada apenas após cessadas quaisquer possibilidades de acordo, hipótese que encontra respaldo no artigo $3^{\circ}$ da Lei 7.783 , de 28 de junho de 1989 - "Exercício do Direito de Greve",

As negociações coletivas são permanentemente estimuladas e a Constituição Federal de 1988 as contempla em vários dispositivos, a exemplo do inciso VI do artigo $8^{\circ}$. Todavia, nenhum interesse de qualquer categoria deverá preponderar sobre o interesse público. Assim não pode ser transacionada nenhuma norma que protege a saúde dos trabalhadores, situados aqui preceitos pertinentes à higiene e à segurança do trabalho, bem como os relativos à integridade moral, nestes compreendidos os direitos à privacidade, à honra, à intimidade e à boa fama.

A Convenção n. 154 da Organização Internacional do Trabalho (OIT), ratificada pelo Brasil em 10 de julho de 1992, em seu artigo $2^{\circ}$ dispõe:

Para efeito da presente Convenção, a expressão 'negociação coletiva' compreende todas as negociações que tenham lugar entre, de uma parte, um empregador, um grupo de empregadores ou uma organização ou várias organizações de empregadores, e, de outra parte, uma ou várias organizações de trabalhadores, com a fim de:

a) fixar as condições de trabalho e emprego; ou

b) regular as relações entre empregadores e trabalhadores; ou

\footnotetext{
${ }^{5}$ Lei 7.783, 28 de junho de 1989: art. $3^{\circ}$. "Frustrada a negociação ou verificada a impossibilidade de recursos via arbitral, e facultada a cessação coletiva do trabalho."
} 
c) regular as relações entre os empregadores ou suas organizações e uma ou várias organizações de trabalhadores, ou alcançar todos estes objetivos de uma só vez.

Percebe-se que normas supranacionais, igualmente incentivam as negociações, como textualmente explicitado no artigo $5^{\circ}$ - 1, da mesma Convenção que diz: "deverão ser adotadas medidas adequadas às condições nacionais no estimulo às negociações coletivas”.

Ainda tratando do papel dos sindicatos nas negociações coletivas, a Carta vigente, estabelece em seu artigo $8^{\circ}$, inciso VI a obrigatoriedade de sua participação em tal procedimento. No entanto, Alice Monteiro de Barros (2008, p. 1243) salienta que, a despeito de o citado inciso fazer menção a "sindicatos" no plural, tal imprescindibilidade concerne apenas ao sindicato profissional em virtude do princípio da tutela, que se aplica apenas ao empregado. Deduz-se daí que o sindicato econômico não carece de participação obrigatória nas negociações, até porque a celebração de acordo coletivo, isto é, o ajuste entre empregados e empresas, com efeito interpartes, desonera a presença do sindicato econômico.

Considerando-se, então, que, para chegar a um consenso em face de um conflito, é indispensável a presença dos envolvidos, pode-se afirmar que é absolutamente necessária a presença e a participação do categoria patronal representada pelo sindicato correlato nas negociações para firmar Convenção Coletiva de Trabalho, ou de uma ou mais empresas no caso de Acordo Coletivo de Trabalho (ACT).

\subsection{ATUAÇÃO SINDICAL EM TEMPOS DE CRISE: DESAFIOS E PERSPECTIVAS}

No Brasil, a fase correspondente aos últimos anos da década 1970 é considerada o marco do ressurgimento dos movimentos sindicais.

Nessa época, ações reivindicatórias ainda eram pouco usuais que, se apresentadas, necessariamente passavam pelo crivo da política econômica. Desse modo, os salários e as condições laborais eram instituídos por meio de decretos governamentais. Esse era o contexto em que se situava o sindicalismo no período compreendido entre 1968 a 1978, no País. 
Após essa etapa, e em decorrência dos movimentos sindicais nascidos das greves de 1978 no ABC paulista, surge o denominado "novo sindicalismo", que se desenvolveu ao longo do período ditatorial remanescente. Foi um período em que os trabalhadores se organizavam e protestavam em frente aos portões das fábricas em desacordo com as diretorias que comandavam os sindicatos e contra a política econômica altamente inflacionária.

Daí se originaram os movimentos sindicais em massa, oportunidade em que as comissões de fábricas, as centrais sindicais, como a CUT (Central Única dos Trabalhadores) ${ }^{6}$ se desenvolveram.

O processo inflacionário da década de 80 foi uma das principais razões para o argumento da ação sindical, em especial para o incremento dos movimentos paredistas em todos os seguimentos de produção, levando à solidificação dos entes sindicais. As negociações coletivas passaram a desempenhar um papel relevante, em substituição às decisões judiciais prolatadas por meio da interposição de dissídio coletivo na Justiça do Trabalho, demonstrando a viabilização do poder de reivindicação reprimido pela ditadura.

O sindicato surge como uma nova estrutura ávida pela concretização dos anseios de uma classe trabalhadora que vivia sob os impactos de um regime político impositivo, além de conviver com um processo inflacionário que impossibilitava uma sobrevivência minimamente digna. No entanto, Márcio Túlio Viana (2003, p. 353) esclarece que

o sindicato tinha os seus limites. Embora se tornasse - tal como a fábrica cada vez mais organizado, nunca foi forte o suficiente para devolver aos trabalhadores os meios de produção. É que sua força vinha do próprio sistema. Era ele quem o alimentava. Fora da fábrica, os trabalhadores tendiam a se dispersar de novo.

\footnotetext{
${ }^{6}$ As centrais sindicais, a exemplo da CUT (Central Única dos Trabalhadores), muito embora não tenham sido concebidas na organização da estrutura sindical assinalada pela Constituição Federal de 1988, exercem papel atuante e fortemente presente nos ajustes das entidades sindicais. Legalmente essas centrais foram reconhecidas pela Lei 11.648, de 31 de março de 2008 como entidades associativas da classe profissional. Não lhes são atribuídos, todavia, os poderes típicos às entidades sindicais, especialmente o de representação jurídica.
} 
Passando à atual conjuntura socioeconômica, o País atravessa um momento singular de crise, cujas causas são inúmeras. O desemprego, cada vez mais presente em todos os campos de atividade, produz efeitos nefastos na vida dos trabalhadores, acarretando além de danos materiais, danos psíquicos. A preocupação e a tensão daí decorrentes afetam sobremaneira todos os assalariados o que, naturalmente, leva ao desenlace de protestos coletivos dos trabalhadores mediados por seus sindicatos.

Diante desse quadro, invoca-se a força sindical para negociar, mesmo que numa situação de desequilíbrio, considerando que o papel do sindicato é assistir os trabalhadores na defesa de seus direitos e em prol de melhores condições de trabalho e, por conseguinte, de vida.

Sabe-se que numa situação dessas o sindicato econômico poderá fazer imposições e estabelecer as regras. Assim, o sindicato profissional deve esforçar-se no sentido de construir um elo de cooperação com o sindicato econômico para que, juntos, encontrarem soluções eficazes para superar os desafios típicos de tempos de crise, criando condições de assegurar o maior número de empregos.

Destarte, os desafios hoje colocados para a ação dos sindicatos são múltiplos diante da expansão exponencial do desemprego. No entanto, juntos os parceiros sociais compreendendose, nesse contexto, as representações profissionais e as econômicas, por meio das negociações, coletivas, têm um papel fundamental, qual seja: o de contribuir para desenvolver programas voltados para minimizar os impactos das dificuldades sócioeconômicas que atingem toda a sociedade.

É imperioso o diálogo social. A interação entre os representantes do trabalho e do capital pode viabilizar as soluções para os problemas que afetam diretamente os trabalhadores, de modo que estes possam enfrentar os percalços impostos pelas atuais dificuldades e que não se retroceda na busca de uma sociedade justa, igualitária, solidária e condescendente. 


\section{CONSIDERAÇÕES FINAIS}

A interferência e a intervenção estatal na organização sindical foram afastadas com o advento da Constituição Federal de 1988, em virtude da afirmação do princípio da autonomia dos sindicatos, sem embargo de ter-se mantido o princípio da unicidade sindical, o que obsta, de certa forma, um sindicalismo absolutamente livre e pluralista no exercício da defesa dos interesses de todos os trabalhadores. Sob este enfoque torna-se premente a necessidade de o Brasil ratificar a Convenção n. 87 da Organização Internacional do Trabalho, de modo que a liberdade sindical seja efetivamente incorporada ao ordenamento jurídico pátrio, evitando-se, assim, a atual anomalia do sistema quanto a esse aspecto.

Apurou-se que a estrutura sindical brasileira, cuja forma é piramidal, tem em sua base os sindicatos; em seu meio, as federações e em seu ápice, as confederações. No que pertine à representação dos trabalhadores, os sindicatos base, organizam-se por categoria profissional ou diferenciada e, em relação aos empregadores, tem-se a categoria econômica. As federações se formam com o agrupamento de, pelo menos, cinco sindicatos da mesma categoria profissional, diferenciada ou patronal, ao passo que as confederações se constituem de, pelo menos, três federações, respeitadas as categorias respectivas.

Outra notável etapa foi a averiguação das prerrogativas e funções preponderantes dos entes sindicais que, até o ano de 1988, refletiam o regime político vivenciado até então, cujo traço significativo era o controle irrestrito e a negativa da liberdade de criação de sindicatos, bem como de sua autonomia através da imposição, para o exercício de suas atividades, do permanente aval do Estado.

Vale ressaltar, ainda, o quão importante é a participação dos sindicatos na celebração de Acordo e Convenção Coletiva de Trabalho, sem a presença dos quais os ajustes entre trabalhadores e seus empregadores não se realiza, destacando-se que tais pactos são precedidos de negociações entre as partes e que são considerados um dos mais relevantes instrumentos na solução de lides trabalhistas de natureza coletiva. 
As circunstâncias socioeconômicas atuais ensejam o momento de crise pelo qual atravessa o Brasil. Em vista disso, exigiu-se uma abordagem das possibilidades de atuação sindical contemporânea, assim como dos desafios inerentes a esse momento singular, com vistas a um novo papel dos sindicatos em negociações relativas à manutenção dos empregos.

Assim, o papel dos sindicatos deve ser repensado diariamente, considerando a sua finalidade primordial na qualidade de representante e defensor das categorias profissionais, a dinamicidade das relações, a pertinência das negociações coletivas, vislumbrando a solução dos impasses que atingem diretamente os trabalhadores, de maneira que estes possam responder aos contratempos resultantes da expansão exponencial do desemprego. De igual maneira, independentemente das circunstâncias negativas atuais, que se mantenha sua importante participação na construção de uma sociedade que enseja a autossuficiência do conjunto de trabalhadores, proporcionando-lhes meios de uma vida digna, compatível com a realização efetiva da democracia e do Estado de direito.

\section{REFERÊNCIAS}

BARros, Alice Monteiro de. Curso de Direito do Trabalho. 4. ed. São Paulo: LTr. 2008. BORBA, Joselita Nopomuceno. Legitimidade Concorrente na Defesa dos Direitos e Interesses Coletivos e Difusos. São Paulo: LTr, 2013.

BRASIL. Câmara dos Deputados. Decreto no 1.637, de 5 de janeiro de 1907. Disponível em: <http://www2.camara.leg.br/legin/fed/decret/1900-1909/decreto-1637-5-janeiro-1907-582195publicacaooriginal-104950-pl.html>. Acesso em: 2 jul. 2015.

BRASIL. Consolidação das Leis do Trabalho. In: COSTA, Armando Cassimiro Costa; MARTINS, Melchíades Rodrigues; CLARO, Sônia Regina da S. Consolidação das Leis do Trabalho. 44. ed. São Paulo: LTr, 2015.

BRASIL. Constituição (1988). Constituição da República Federativa do Brasil. Disponível em: <http://www.planalto.gov.br/ccivil_03/constituicao/constituicaocompilado.htm>. Acesso em: 2 jul. 2015. 
BRASIL. Lei 7.783, 28 de junho de 1989. Dispõe sobre o exercício do direito de greve, define as atividades essenciais, regula o atendimento das necessidades inadiáveis da comunidade, e dá outras providências. Disponível em: 〈http://www.planalto.gov.br/Ccivil_03/LEIS/L7783.htm>. Acesso em: 04 jul. 2015.

BRASIL. Supremo Tribunal Federal. Súmula 677. Disponível em: <http://www.stf.jus.br/portal/cms/verTexto.asp?servico=jurisprudenciaSumula\&pagina=sumula 601_700>. Acesso em: 2 jul. 2015.

BRASIL. Tribunal Superior do Trabalho. Jurisprudências. Disponível em: <http://www3.tst.jus.br/jurisprudencia/PN_com_indice/PN_completo.htm>. Acesso em: 4 jul. 2015.

CARRION, Valentin. Comentários à Consolidação das Leis do Trabalho. 37. ed. atualizada por Eduardo Carrion. São Paulo: Saraiva, 2012.

CESARINO JÚNIOR, Antonio Ferreira. Direito Social. São Paulo: LTr. 1980.

EÇA, Vitor Salino de Moura. Substituição Processual Sindical no Processo do Trabalho. Revista do TRT da 3ª Região, Belo Horizonte, v. 46, p. 219-234, jul./dez. 2007.

LOSANO, Nestor de Buen. Derecho del trabajo. México: Porruá, 1977.

MANFREDI, Maria. Formação sindical no Brasil. História de uma prática cultura. São Paulo: Escrituras, 1996.

NASCIMENTO, Amauri Mascaro do. Direito Sindical. São Paulo: Saraiva, 1989.

NASCIMENTO, Amauri Mascaro do. Compendio do Direito Sindical. 2. ed. São Paulo: LTr, 2000.

ORGANIZAÇÃO INTERNACIONAL DO TRABALHO. Convenção n. 87. Disponível em: <http://www.oitbrasil.org.br/sites/default/files/topic/union_freedom/doc/convention_87_171.pd f>. Acesso em: 04 jul. 2015. 
RUPRECHT, Alfredo J. Relações coletivas de trabalho. São Paulo: LTr, 1995. SANTOS, Ronaldo Lima dos. Sindicato e Ações Coletivas. 3. ed. São Paulo: LTr, 2012.

VIANA, Márcio Túlio. O Sindicato e a proteção ao emprego. In: VIDOTTI, Tárcio José; GIORDANI, Francisco Alberto da Motta Peixoto. Direito Coletivo do Trabalho em uma Sociedade Pós-Industrial. São Paulo: LTr, 2003.

VIANNA, Segadas. Organização sindical: In: SUSSEKIND, Arnaldo; MARANHÃO, Délio; VIANNA, Segadas. Instituições do direito do trabalho. 11. ed. São Paulo: LTr, 1991. 